\title{
Acceptance and Tolerability of an Adjuvanted nH1N1 Vaccine in HIV-infected Patients in the Cologne-Bonn Cohort
}

\author{
B. Steffens ${ }^{1 *}$, T. Kümmerle ${ }^{*}$, S. Koch ${ }^{1}$, A. Birtel ${ }^{1}$, C. Schwarze-Zander ${ }^{2}$, J. Emmelkamp ${ }^{2}$, W. V. Kern³, \\ C. Hertenstein ${ }^{1}$, C. Wyen ${ }^{1 \#}$, C. Lehmann ${ }^{1 \#}$, O. A. Cornely ${ }^{1,4}$, J. Rockstroh², G. Fätkenheuer ${ }^{1 \#}$ \\ $11^{\text {st }}$ Department of Internal Medicine, University of Cologne, Cologne, Germany \\ ${ }^{2}$ Department of Medicine, University of Bonn, Bonn, Germany \\ ${ }^{3}$ Center for Infectious Diseases and Travel Medicine, University Hospital Freiburg, Freiburg, Germany \\ ${ }^{4}$ Zentrum für Klinische Studien - ZKS Köln, BMBF 01KN0706, CIO KölnBonn, and Cologne Excellence Cluster on Cellular Stress \\ Responses in Aging-Associated Diseases (CECAD), University of Cologne, Cologne, Germany
}

\begin{abstract}
Objective: To evaluate the acceptance and tolerability of the nH1N1 2009 vaccine in HIV-positive individuals.

Method: 758 patients were included in this prospective study. Different study populations were formed: The Tolerability Study Group consists of HIV-infected patients who visited three outpatient clinics (Cologne, Bonn, Freiburg) during a predefined time period. Patients were offered nH1N1 vaccination. Those accepting were administered a standard dose AS03 adjuvant nH1N1 vaccine. Questionnaires to report side effects occurring within 7 days after immunization were handed out.

In a substudy conducted during the same time period, acceptance towards immunization was recorded. This Acceptance Study Group consists of all HIV-infected patients visiting the Cologne clinic. They were offered vaccination. In case of refusal, motivation was recorded.

Results: In the Tolerability Study Group, a total of 475 patient diaries returned in the three study centres could be evaluated, 119 of those $(25 \%)$ reported no side effects. Distribution of symptoms was as follows: Pain 285/475 patients $(60 \%)$, swelling 96 (20\%), redness $54(11 \%)$, fever $48 / 475(10 \%)$, muscle/joint ache 173 (36\%), headache 127 (27\%), and fatigue 210 (44\%). Association of side effects with clinical data was calculated for patients in Cologne and Bonn. Incidence of side effects was significantly associated with CDC stages A, B compared to $\mathrm{C}$, and with a detectable viral load ( $>50$ copies $/ \mathrm{mL}$ ). No correlation was noted for CD4 cell count, age, gender or ethnicity.

In the Acceptance Study Group, 538 HIV-infected patients were offered vaccination, $402(75 \%)$ accepted, while $136(25 \%)$ rejected. Main reasons for rejection were: Negative media coverage (35\%), indecisiveness with preference to wait until a later date $(23 \%)$, influenza not seen as personal threat $(19 \%)$ and scepticism towards immunization in general $(10 \%)$.
\end{abstract}

\footnotetext{
* Both authors have contributed equally to the study.

\# Supported bei „Bundesministerium für Bildung und Forschung“" (BMBF) grant $01 \mathrm{KI} 0771$
}

Conclusion: A total of $622 \mathrm{HIV}$-infected patients were vaccinated against $\mathrm{nH} 1 \mathrm{~N} 1$-influenza in the three study centres. No severe adverse events were reported. The tolerability was in most parts comparable to general population. Acceptance rate towards influenza vaccination was high $(75 \%)$. Those refusing the immunization mentioned negative media coverage as the major influence on their decision.

Key words: nH1N1, influenza, HIV, vaccine, tolerability, adverse events, safety, acceptance

\section{INTRODUCTION}

A novel swine-origin influenza A (H1N1) virus strain was first described in April 2009 in Mexico and the USA [1]. It rapidly spread worldwide and caused a large number of infections and deaths. In Germany, the first cases were identified in April [2], numbers rose to more than 15.000 documented cases until the end of August [3] and the first attributable death in Germany occurred in September 2009 [4].

The WHO declared a pandemic in June 2009, which, in Germany, led to the implementation of a pre-existing pandemia emergency plan (http://www. rki.de/cln_160/nn_1960682/DE/Content/InfAZ/I/ Influenza/Influenzapandemieplan.html; last accessed September 20, 2010). Among other recommendations and guidelines, this plan recommended active immunization as the most effective approach to reduce illness and death from pandemic influenza based on a risk-benefit analysis. In September 2009, the European Commission licensed two adjuvant vaccines, of which the monovalent AS03 adjuvant vaccine Pandemrix ${ }^{\circledR}$ was used in Germany [5]. Pandemrix ${ }^{\circledR}$ contains inactivated, split influenza virus with antigen equivalent to A/California/7/2009 (H1N1)v-like strain (X-179A).

On October 2nd 2009, the Federal German Vaccination Committee (STIKO) issued a common recommendation for the immunization with Pandemrix ${ }^{\circledR}$, in particular for people aged 6 years and older with increased health risks as consequence of an underlying chronic disease [6]. These recommendations include patients with HIV infection. 
HIV-infected patients have a higher risk of complications and critical course of disease regarding seasonal influenza [7-9]. It has been shown that influenza vaccination is safe, and only rarely influences viral load and CD4 cell count. Changes of these parameters appeared to be transient and no effect on the progress of the HIV infection could be seen [10]. Effectiveness of an immunization against seasonal influenza has been demonstrated in several studies [11]. Thus annual vaccination against seasonal influenza in HIV patients is part of standard recommendation in Germany [12].

The aim of this study was to show the acceptance and tolerability towards the active immunization with Pandemrix ${ }^{\circledR}$ in a cohort of HIV infected out-patients.

\section{METHODS}

In this prospective multicenter study, all patients in Cologne, Bonn and Freiburg vaccinated with Pandemrix ${ }^{\circledR}$ who returned their patient questionnaire were included in the Tolerability Study Group. In a substudy in Cologne, acceptance of vaccination was investigated among all HIV-infected patients eligible for influenza vaccination seen during the same time period in Cologne (Acceptance Study Group). Cologne patients who were immunized and returned their questionnaire were included in both study groups (Fig. 1).

This study was approved by local ethics committees.

\section{TOLERABILITY}

The Tolerability Study Group consists of all HIV-infected patients who were vaccinated with Pandemrix ${ }^{\circledR}$ from $2^{\text {nd }}$ November to $23^{\text {rd }}$ December 2009 in the three institutions mentioned above. Additionally, these patients were given a patient diary to be used to record symptoms, including their duration and severity over a period of 7 days after vaccination. The symptoms were grouped into both local at the injection site such as pain, redness, and swelling, and systemic symptoms such as fever (above $38.0^{\circ} \mathrm{C}$ ), muscle and joint pain, headache and fatigue. If no symptoms occurred, the diary was to be left blank but handed in nonetheless.

The classification of severity used is based on the Common Toxicity Criteria for Adverse Events (CTCAE) v4.0, ranging from 1 (mild) over 2 (moderate) and 3 (severe) to 4 (life threatening) (http://evs.nci. nih.gov/ftp1/CTCAE/Archive/CTCAE_4.01_200907-14_QuickReference_5x7.pdf; last accessed September 20, 2010). The diameter of local swelling and redness was to be reported in millimetres. Patients were asked to return the diary in a provided, pre-stamped envelope.

\section{ACCEPTANCE}

The Acceptance Study Group comprises all HIV-infected patients, who were treated at the outpatient ward in Cologne during the same time period and did not meet any of the exclusion criteria for vaccination. All patients were informed about novel influenza and the risks and benefits of active immunization. Those who rejected vaccination were interviewed regarding their motives for rejection. They could choose among the following set of answers: 1) advise against immunization by family doctor; 2) scepticism towards vaccination in general; 3) negative media coverage; 4) previous reactions to vaccination in family members or friends; 5) Novel influenza not considered as a personal threat; 6) adverse events in the past; 7) preference to wait until a later date to get vaccinated.

\section{VACCINATION}

Exclusion criteria for vaccination with Pandemrix ${ }^{\circledR}$ included: Current fever; previous intolerance or allergies to egg protein or components of the vaccine; previous intolerance to vaccinations in general; first trimester

Acceptance Study Group ( $\mathrm{N=538)}$ vact

Fig. 1. Profile of participants in this study. 
pregnancy. Another exclusion criterion was previous vaccination against the pandemic H1N1 influenza at another institution.

Those eligible were administered the standard dose of Pandemrix ${ }^{\circledR}$ into the deltoid muscle. It contained $3.75 \mu \mathrm{g}$ hemagglutinin of inactivated, propagated in eggs, split influenza virus (A/California/7/2009 (H1N1)-like strain (X-179A)). The antigen production equals that of the seasonal vaccine Influsplit ${ }^{\circledR}$ (Glaxo Smith Kline, Dresden, Germany). The AS03 adjuvant consists of squalene (10.69 mg), DL- $\alpha$-tocopherol $(11.86 \mathrm{mg})$ and polysorbate $80(4.86 \mathrm{mg})$. Furthermore, a standard dose contains $5 \mathrm{~g}$ thiomersal as preservative.

\section{STATISTICAL ANALYSis}

Nominal values were compared using the [chi]2 test. Statistical analyses were performed using Microsoft Excel 2008 for Mac, (Microsoft Corp., Redmond, Washington, USA) and SPSS, release 17 (SPSS Inc., Chicago, Illinois, USA).

\section{RESULTS}

The demographic and HIV-related parameters for the two study groups listed in Table 1.

\section{TOLERABILITY}

The Tolerability Study Group comprises 475 patients who returned their questionnaire in the three study centres, 255 in Cologne, 175 in Bonn and 45 in Freiburg.

No symptoms at all were reported by 119 of 475 $(25 \%)$ patients. $77(16 \%)$ reported local symptoms only, $55(12 \%)$ systemic symptoms only and $224(47 \%)$ developed both local and systemic symptoms (Table 2).

Analysis of association of symptoms with clinical data was performed on patients in Cologne and Bonn.
Table 1. Demographic and HIV-related parameters.

\begin{tabular}{|c|c|c|}
\hline Tolerability Study Group & \multicolumn{2}{|c|}{$\begin{array}{l}\text { HIV infected patients vaccinated } \\
\text { against pandemic influenza in the } \\
\text { two centres who returned their } \\
\text { patient's diary }\end{array}$} \\
\hline Acceptance Study Group & \multicolumn{2}{|c|}{$\begin{array}{l}\text { HIV infected patients, eligible for } \\
\text { active immunization, who visited } \\
\text { the Cologne outpatient clinic in } \\
\text { the predefined time period }\end{array}$} \\
\hline SD & \multicolumn{2}{|c|}{ Standard deviation } \\
\hline ART & \multicolumn{2}{|c|}{ Antiretroviral therapy } \\
\hline & $\begin{array}{l}\text { Tolerability } \\
\text { Study Group }\end{array}$ & $\begin{array}{l}\text { Acceptance } \\
\text { Study Group }\end{array}$ \\
\hline $\mathrm{N}$ (total) & 475 & 538 \\
\hline Male:Female & $387: 88$ & 447:91 \\
\hline Mean age, years (SD) & $45( \pm 9)$ & $45( \pm 9)$ \\
\hline Caucasian, N (\%) & $404(85 \%)$ & $453(84 \%)$ \\
\hline $\begin{array}{l}\text { Mean absolute CD4-cells/ } \\
\mu \mathrm{l} \text { (SD) }\end{array}$ & $498( \pm 194)$ & $483( \pm 177)$ \\
\hline $\begin{array}{l}\text { HIV-RNA }<50 \text { copies / } \\
\text { ml, N }(\%)\end{array}$ & $336(77 \%)$ & $393(73 \%)$ \\
\hline ART treatment, $\mathrm{N}(\%)$ & $412(87 \%)$ & $462(86 \%)$ \\
\hline
\end{tabular}

Patients from Freiburg could not be included, since the informed consent in Freiburg did not cover this analysis. Those developing any symptoms were more likely to have CDC stages A and B $(248 / 318,78 \%)$ than stage $\mathrm{C}(73 / 107$ cases, $68 \% ; \mathrm{P}=0.042)$ and were also more likely to have a detectable viral load greater than $50 \mathrm{HIV}-1$ RNA copies/mL (79/95, (83\%)) compared to $142 / 202(70 \%)$ patients with undetectable viral load $(\mathrm{P}=0.018)$. No statistically significant association was found between the presence of symptoms and age, gender, ethnicity or CD4 cell count.

Table 2. Reported side effects (total number $=475$ )

\begin{tabular}{|c|c|c|c|c|c|c|c|}
\hline & \multirow[t]{2}{*}{ Occurrence } & \multirow[t]{2}{*}{ Mean duration } & \multirow[t]{2}{*}{ Mean severity } & \multicolumn{4}{|c|}{ Grade of Severity } \\
\hline & & & & 1 & 2 & 3 & 4 \\
\hline & $\mathrm{N}(\%)$ & Days (SD) & $(*)$ & $\mathrm{N}(\%)$ & $\mathrm{N}(\%)$ & $\mathrm{N}(\%)$ & $\mathrm{N}(\%)$ \\
\hline & & & & & & \multicolumn{2}{|c|}{ Local symptoms } \\
\hline Pain & $285(60 \%)$ & $2.9( \pm 1,1)$ & $1.4( \pm 0.5)$ & $200(42 \%)$ & $69(15 \%)$ & $16(3 \%)$ & $0(0 \%)$ \\
\hline Swelling & $95(20 \%)$ & $2.6( \pm 1.3)$ & $14.8( \pm 17.1) \dagger$ & $\because$ & $\because$ & $\because$ & $\because$ \\
\hline Redness & $52(11 \%)$ & $3.1( \pm 1.5)$ & $14.8( \pm 17.1) \dagger$ & $\because$ & $\therefore$ & $\therefore$ & $\because$ \\
\hline & & & & & & \multicolumn{2}{|c|}{ Systemic symptoms } \\
\hline Fever & $47(10 \%)$ & $2.0( \pm 1.0)$ & $1.2( \pm 0.3)$ & $41(9 \%)$ & $6(1 \%)$ & $1(0 \%)$ & $0(0 \%)$ \\
\hline Muscle/jointache & $172(36 \%)$ & $2.7( \pm 1.3)$ & $1.4( \pm 0.5)$ & $121(25 \%)$ & $38(8 \%)$ & $14(3 \%)$ & $0(0 \%)$ \\
\hline Headache & $126(27 \%)$ & $2.5( \pm 1.5)$ & $1.4( \pm 0.6)$ & $93(20 \%)$ & $21(4 \%)$ & $13(3 \%)$ & $0(0 \%)$ \\
\hline Fatigue & $207(44 \%)$ & $2.8( \pm 1.5)$ & $1.5( \pm 0.6)$ & $125(26 \%)$ & $65(14 \%)$ & $20(4 \%)$ & $0(0 \%)$ \\
\hline
\end{tabular}

SD Standard deviation

(*) Severity: from 1 (mild) to 4 (life threatening), according to CTCAE v4.0 criteria (except severity of "swelling" and "redness", see below)

$\dagger$ Severity of "swelling" and "redness": mean diameter (standard deviation) in millimeters

$\because$ no grading system was used 


\section{ACCEPTANCE}

In the same time period, a total of $588 \mathrm{HIV}$-infected patients visited the outpatient clinic in Cologne, of which $50(9 \%)$ were excluded from vaccination. Reasons for exclusion were: Forty-one out of $588(7 \%)$ had previously been vaccinated against $\mathrm{nH} 1 \mathrm{~N} 1$ influenza at a different institution and 9 out of $588(2 \%)$ met a medical contraindication (5 patients suffered from acute febrile infection and 4 were pregnant in the first Trimester).

Hence the Acceptance Study Group consists of 538 patients, of which $402 / 538(75 \%)$ agreed to being vaccinated, whereas 136 out of 538 (25\%) refused vaccination. Reasons for rejection are shown in Figure 2.

No significant differences were noted between those accepting or refusing vaccination regarding age, gender, ethnicity, CD4 count, viral load or CDC stage.

In the Acceptance Study Group, 255 out of $402 \mathrm{pa}$ tients $(63 \%)$ returned their diary and are therefore part of the Tolerability Study Group as well, while 147 did not return it $(37 \%)$. Those having returned the questionnaires were significantly more likely to have a CD4-cell count above 200 cells/ $\mu \mathrm{L}(243 / 255$ (95\%) vs. $129 / 147$ (88\%); $\mathrm{P}=0.006)$. Additionally, they were more likely to be within CDC stage A or B vs. CDC stage C (181/255 (71\%) vs 90/147 (61\%); P = 0.044). No significant association considering viral load, ethnicity, age or gender was found.

\section{Discussion}

Among the HIV-infected patients in the Acceptance Study Group, vaccination with Pandemrix ${ }^{\circledR}$ reached an acceptance rate of $75 \%$. This shows that very high immunization rates can be achieved in selected populations. In contrast, the average 2009 pandemic vaccine coverage in the German population is between 6.8\% and $8 \%[13,14]$. This discrepancy might primarily be caused by the high frequency of doctor-patient en- counters within the HIV-treatment setting, allowing patients to gather medical information about the benefits of influenza vaccination easily. Secondly, a good level of self-education of HIV-patients about healthrelated subjects can often be found, which might lead to positive health-seeking behaviour.

For the general population in Germany, it has been shown that media, such as television, radio and print, were the major source of information regarding the nH1N1 pandemic. Fifty-five percent of those questioned in a German telephone survey reported that they felt insecure about influenza vaccination because of conflicting media reports[15]. In our cohort, this is reflected by the fact that negative media coverage followed by indecisiveness were the main reasons of rejection of vaccination.

Of the 402 distributed patient questionnaires in Cologne, 255 were handed back (63\%). The patient groups returning the diaries versus those failing to do so did not differ regarding viral load, age, gender or ethnicity. However, those not having returned it were significantly more likely to have a CD4-cell count below $200 / \mu \mathrm{L}$ and/or be categorized into CDC stage C. Among the reasons for failing to send back the diary might be a general lack of compliance in those patients which could in turn be among the reasons responsible for having achieved advanced disease stages. It could also be related to the reduced state of mental and physical health of those patients leading to limited mobility and failure to comply with study requirements, i.e. to complete and return the questionnaires in due time.

Information on adverse events of the 402 patients vaccinated in Cologne was not only collected by evaluation of patient questionnaires, but also by information obtained in regular patient visits. This results in the total number of 622 patients with no severe adverse events after the vaccination in all three study centres.

Data on the tolerability of the vaccine in healthy adults are available from a phase III study conducted by GSK Biologicals, the manufacturer of Pandemrix ${ }^{\circledR}$

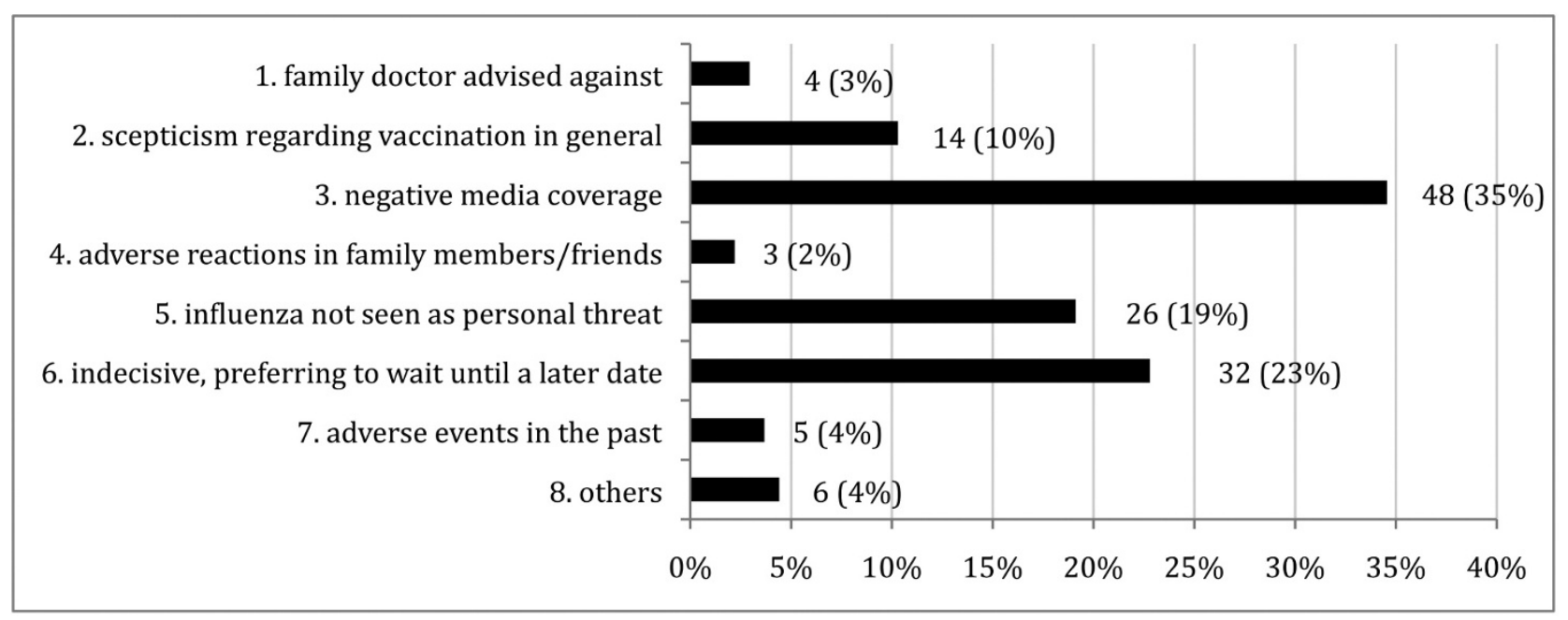

Fig. 2. Reasons to reject the vaccination.

HIV infected patients, visiting the outpatient clinic in Cologne in a predefined time period and generally suitable for an active immunization, were offered a pandemic influenza vaccination. If rejected, reasons for the refusal were recorded with the help of the preset answers 1-8. (total $\mathrm{N}=136$ ) 
(Study 113630, NCT00975884; http://download.gskclinicalstudyregister.com/files/28342.pdf; last accessed September 20, 2010). The subjects included 162 healthy adults aged 18 to 60 .

Compared to a matched subset within our Tolerability Study Group (limited to those at age 18-60 years, $\mathrm{N}=423$ ), GSK-study participants had a similar mean age (40 years vs. 43 years in HIV-infected patients) and gender allocation was more balanced ( $47 \%$ male participants in the GSK study vs. $81 \%$ men in our HIV cohort).

The following differences regarding occurrence of symptoms 7 days after the application of the first dose of Pandemrix ${ }^{\circledR}$ are apparent. Pain at the injection site was reported much less frequently in our study than in the GSK study $(261 / 423(62 \%)$ vs. 154/162 (95\%)). On the other hand, HIV-patients in our study reported fever (defined as $\geq 38.0{ }^{\circ} \mathrm{C}$ ) more often (46/423 patients; $11 \%$ ) than participants in the GSK study $\left(3 / 162 ; 2 \%\right.$, fever defined as $\left.\geq 37.5^{\circ} \mathrm{C}\right)$.

As injection site reactions such as pain are most often caused by local immune reactions, impaired reactiveness of the immune system to vaccinations due to HIV infection might explain the lower number of local symptoms observed in our study group. The fact that symptoms within the HIV+ cohort occurred irrespective of CD4-count might correspond to an impaired immune capacity not reflected by CD4-count alone. The reasons for the higher rates of fever observed in our HIV-cohort remain unclear at that point.

While this study did not investigate on the effectiveness of the vaccination, several studies on the immunogenicity of pandemic influenza vaccines in HIV patients are available [16-20].

At the same time, data on the tolerability of an AS03-adjuvanted vaccine in HIV-infected patients has only been shown by TREMBLAY et al. for a smaller group of participants $(\mathrm{N}=84)$ [20]. Results are in a comparable range to the results in this study. Active immunization with the AS03 adjuvant appears to be safe and well tolerated in HIV-infected patients.

\section{CONCLUSION}

A total of $622 \mathrm{HIV}$-infected patients were vaccinated against nH1N1-Influenza using adjuvantated vaccine. No severe adverse events were reported. The vaccine was well tolerated. Rates of side effects were similar to those seen in comparable studies with HIV-negative participants. Acceptance rate of influenza vaccination was high among HIV-infected patients (75\%). Those refusing the immunization mentioned negative media coverage as the major influence on their decision

Acknowledgments: GF, CW and CL are supported by the German Federal Ministry of Research and Education (BMBF grant 01KI0771).

\section{REFERENCES}

1. Dawood FS, Jain S, Finelli L, Shaw MW, Lindstrom S, Garten RJ, Gubareva LV, Xu X, Bridges CB, Uyeki TM. Emergence of a novel swine-origin influenza A (H1N1) virus in humans. N Engl J Med. 2009 Jun 18;360(25): 2605-15.
2. team NiAHNi. Description of the early stage of pandemic (H1N1) 2009 in Germany, 27 April-16 June 2009. Euro Surveill. 2009 Aug 6;14(31).

3. Gilsdorf A, Poggensee G. Influenza $A(H 1 N 1) v$ in Germany: the first 10,000 cases. Euro Surveill. 2009; 14(34).

4. RKI RKI. Zur aktuellen Situation bei ARE/Influenza für die 39. Kalenderwoche 2009. Epid Bull. 2009(40):1.

5. Johansen K, Nicoll A, Ciancio BC, Kramarz P. Pandemic influenza A(H1N1) 2009 vaccines in the European Union. Euro Surveill. 2009;14(41):19361.

6. (RKI) RKI. Notice of the Permanent Vaccination Committee (Ständigen Impfkommission (STIKO)) of the Robert Koch-Institute for the vaccination against the novel influenza A (H1N1). Epid Bull. 2009(41):22.

7. Kunisaki KM, Janoff EN. Influenza in immunosuppressed populations: a review of infection frequency, morbidity, mortality, and vaccine responses. Lancet Infect Dis. 2009 Aug;9(8):493-504.

8. Lin JC, Nichol KL. Excess mortality due to pneumonia or influenza during influenza seasons among persons with acquired immunodeficiency syndrome. Arch Intern Med. 2001 Feb 12;161(3):441-6.

9. Neuzil KM, Reed GW, Mitchel EF, Jr., Griffin MR. Influenza-associated morbidity and mortality in young and middle-aged women. JAMA. 1999 Mar 10;281(10):9017.

10. Zanetti AR, Amendola A, Besana S, Boschini A, Tanzi E. Safety and immunogenicity of influenza vaccination in individuals infected with HIV. Vaccine. 2002 Dec 20;20 Suppl 5:B29-32.

11. Atashili J, Kalilani L, Adimora AA. Efficacy and clinical effectiveness of influenza vaccines in HIV-infected individuals: a meta-analysis. BMC Infect Dis. 2006;6: 138.

12. RKI RKI. Empfehlungen der Ständigen Impfkommission (STIKO) am Robert Koch-Institut/Stand: Juli 2010. Epid Bull. 2010(30): 20.

13. Wichmann O, Stocker P, Poggensee G, Altmann D, Walter D, Hellenbrand W, Krause G, Eckmanns T. Pandemic influenza A(H1N1) 2009 breakthrough infections and estimates of vaccine effectiveness in Germany 2009-2010. Euro Surveill. 2010;15(18).

14. RKI RKI. Repräsentative telefonische Erhebung zur Impfung gegen die pandemische Influenza (H1N1) 2009. Epidemiologisches Bulletin. 2010(25):2.

15. RKI RKI. Telefonische Erhebung zur Impfung gegen die pandemische Influenza (H1N1) 2009. Epid Bull. 2010 (13):2.

16. Bickel M, Wieters I, Khaykin P, Nisius G, Haberl A, Stephan C, Von Hentig N, Herrmann E, Doerr HW, Brodt HR, Allwinn R. Low rate of seroconversion after vaccination with a split virion, adjuvanted pandemic H1N1 influenza vaccine in HIV-1-infected patients. AIDS. 2010 Jun 1;24(9):F31-5.

17. Tebas P, Frank I, Lewis M, Quinn J, Zifchak L, Thomas A, Kenney T, Kappes R, Wagner W, Maffei K, Sullivan K. Poor immunogenicity of the H1N1 2009 vaccine in well controlled HIV-infected individuals. AIDS. 2010 Sep 10;24(14):2187-92.

18. Orlando G, Pariani E, Mazza F, Tanzi E, Meraviglia P, Gianelli E, Argenteri B, Amendola A, Galli M, Rizzardini $G$, Zanetti A. Pandemic influenza vaccine in adult HIV-1-infected patients. AIDS. 2010 Aug 24;24(13): 2142-3.

19. Ho J, Moir S, Wang W, Posada JG, Gu W, Rehman MT, Dewar R, Kovacs C, Sneller MC, Chun TW, Follmann DA, Fauci AS. Enhancing effects of adjuvanted 2009 pandemic $\mathrm{H} 1 \mathrm{~N} 1$ influenza A vaccine on memory B-cell responses in HIV-infected individuals. AIDS. 2011 Jan 28;25(3):295-302. 
20. Tremblay CL, Rouleau D, Fortin C, Toma E, Sylla M, Cyr L, Cote S, Baz M, Sampalis J, Trautman L, Sekaly RP, Boivin G. Immunogenicity and tolerability of an inactivated and adjuvanted pandemic H1N1 influenza vaccine, in HIV-1-infected patients. Vaccine. 2011 Feb 4;29(7): 1359-63.

Received: January 24, 2011 / Accepted: April 1, 2011
Address for correspondence:

Gerd Fätkenheuer, MD

University of Cologne

Department of Internal Medicine I

Kerpener Str. 62

50924 Köln

Germany

Tel.: $\quad+49221478-4175 /-5860$

Fax: $\quad+49221478-5915$

E-mail: gerd.faetkenheuer@uk-koeln.de 